\title{
STRUCTURAL PERFORMANCE EVALUATION OF COLUMN-NUKI CONNECTION IN TRADITIONAL JAPANESE WOODEN BUILDINGS
}

\author{
SATSUKI MURAI ${ }^{*}$ AND MITSUHIRO MIYAMOTO ${ }^{2}$ \\ ${ }^{1}$ Division of Safety Systems Construction, Graduate School of Engineering, Kagawa University \\ 2217-20 Hayashi-cho, Takamatsu, Kagawa 761-0396, Japan \\ e-mail:s19g407@stu.kagawa-u.ac.jp (*corresponding author) \\ ${ }^{2}$ Department of Engineering and Design, Faculty of Engineering and Design, Kagawa University \\ 2217-20 Hayashi-cho, Takamatsu, Kagawa 761-0396, Japan \\ email: miyamoto@eng.kagawa-u.ac.jp; Web page: https://www.kagawa-u.ac.jp/kagawa-u_ead/
}

Keywords: Traditional Japanese wooden buildings, column-nuki connection, seismic performance evaluation

\begin{abstract}
Traditional Japanese wooden buildings have been constructed using internal wooden frame structures. Plus-shaped column-nuki connections are important to evaluate the seismic performance of these buildings, and these connections include several joint types, one of which is the oblique scarf joint. However, only very few extant studies have examined column-nuki connections and oblique scarf joints. Consequently, no design equations exist for this combination. Therefore, it is possible that the structural performance of column-nuki connections might be inaccurately evaluated. Thus, this study aims to evaluate the structural performance evaluation of column-nuki connections in traditional Japanese wooden buildings. Full-scale tests were performed on specimens with either the continuous or oblique scarf joint nuki, and results obtained were compared based on parameters, such as the type of connection and number of dimensions. Subsequently, corresponding analytical results were calculated using an extant design equation, and the same were compared against experimental values to determine the validity of using the design equation for column-nuki connections in traditional Japanese wooden buildings. Results obtained in this study demonstrate the initial stiffness to be approximately identical for specimens with continuous or oblique scarf joint nuki. The yield and ultimate bending moment of oblique scarf joint nuki specimens were observed to be approximately 10-70\% smaller compared to those corresponding to continuous nuki specimens. In addition, all oblique scarf joint nuki specimens demonstrated an initial cleavage failure followed by multiple failures. Results of these comparisons demonstrate that failure can be partially estimated using the extant design equation considered in this study.
\end{abstract}




\section{INTRODUCTION}

Traditional wooden buildings in Japan, such as temples and shrines, demonstrate high deformability, and they can resist large lateral forces during earthquakes. Since ancient times, these traditional buildings have been constructed using column-nuki connections. The construction technique involves building a whole wall around the periphery with the inner structure comprising wooden frames. Column-nuki connections used in the construction of Japanese shrines and temples are larger compared to those used in residential houses. Consequently, some walls of ancient Japanese buildings can resist large lateral forces during earthquakes. Thus, column-nuki connections can be considered important elements during structural performance evaluation of traditional Japanese buildings. However, as shown in reference [1], very few experiments have been conducted on large column-nuki connections and of those, even fewer have been conducted on oblique scarf joint nuki connections, a popular connection type, in traditional wooden Japanese buildings. In seismic evaluations of traditional Japanese houses, the extant design equation has been considered only for continuous nuki. As shown in reference [2], oblique scarf joint nuki are evaluated as 0.5 of the design equation for continuous nuki in traditional Japanese houses. Therefore, there exists a possibility that structural-performance evaluations of column-nuki connections with oblique scarf joint nuki are inaccurate.

The study aims to evaluate the structural performance of column-nuki connections in traditional Japanese wooden buildings. To this end, full-scale tests were performed on plusshaped column-nuki donnections used in Japanese shrine and temple construction. Results these tests were compared against those obtained using the relationship between deformation angle and bending moment as well as scarf joint muki. Details concerning these full-s
manuscript, whereas section 3 discusses the valicit the said plus-shaped column-nuki connection. The comparing analytical results against experimental values pertaining to both continuous and

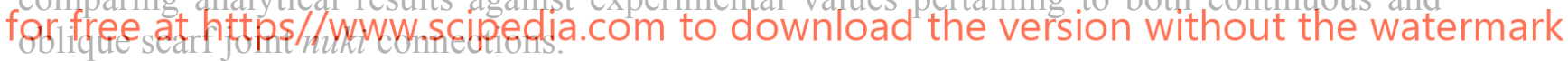

\section{FULL-SCALE TEST OF PLUS-SHAPED COLUMN-NUKI CONNECTION}

In this study, full-scale tests of specimens with continuous or oblique scarf joint nuki were conducted to examine the seismic performance of plus-shaped column-nuki connections. The relationship between the bending moment and deformation angle as well as the failure property were investigated. The test parameters were chosen to examine the seismic performance of a plus-shaped column-nuki specimen, which had either continuous or oblique scarf joint nuki. Both of these have been used for traditional Japanese wooden buildings in the past.

\subsection{Outline of full-scale tests}

Tables 1 and 2 provide information about the specimens examined in the study. A total of sixteen specimens were tested; eight contained continuous nuki, and eight contained oblique scarf joint nuki. All specimens were plus shaped, and the lengths of both the nuki and the column were $1,400 \mathrm{~mm}$. The test specimens were labeled as $\mathrm{C}$ for continuous nuki and $\mathrm{J}$ for oblique 
scarf joint nuki. For the continuous nuki specimens, one condition was different for each specimen based on C1. Figure 1 (a) depicts a drawing of the continuous nuki joint, whereas Figure 1 (b) depicts that corresponding to a continuous nuki with cogged $\mathrm{C} 4$ joint. All specimens, except $\mathrm{C} 5$, have wedges. The oblique scarf joint nuki specimens come in two geometries, as shown in Figures 1 (c) and (d). The numbers right after J in the specimens' name correspond to those mentioned in the list of continuous nukis.

The image of the loading device is shown in Figure 2. The specimen was fixed using a jig. In these tests, positive and negative sides are defined as the left and right sides, respectively, and the negative side contains the wedge. The specimen was subjected to cyclic lateral loads, and the apparent shear deformation angle of a nuki $\gamma_{0}$ was gradually increased symmetrically from $1 / 200,1 / 150,1 / 100,1 / 75,1 / 50,1 / 30,1 / 20,1 / 15$, to $1 / 10 \mathrm{rad}$. One cycle of loading was applied. Finally, the specimen was subjected to a lateral load at an angle of $1 / 7 \mathrm{rad}$ at one end. Figure 3 depicts the full-scale test setup.

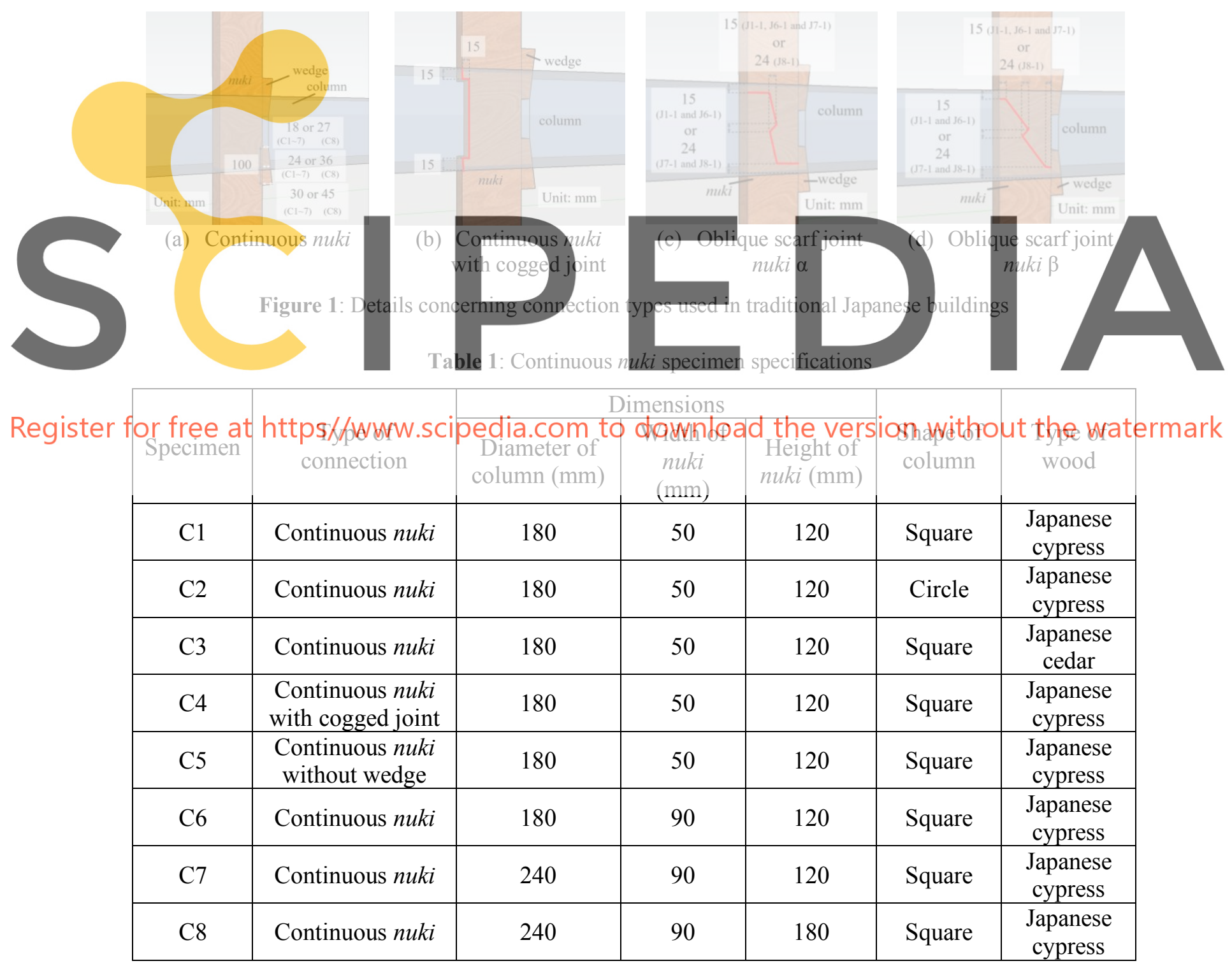


Table 2: Oblique scarf joint $n u k i$ specimen specifications

\begin{tabular}{|c|c|c|c|c|c|c|}
\hline \multirow[b]{2}{*}{ Specimen } & \multirow[b]{2}{*}{$\begin{array}{c}\text { Type of } \\
\text { connection }\end{array}$} & \multicolumn{3}{|c|}{ Dimensions } & \multirow[b]{2}{*}{$\begin{array}{l}\text { Shape of } \\
\text { column }\end{array}$} & \multirow[b]{2}{*}{$\begin{array}{l}\text { Type of } \\
\text { wood }\end{array}$} \\
\hline & & $\begin{array}{c}\text { Diameter of } \\
\text { column }(\mathrm{mm})\end{array}$ & $\begin{array}{c}\text { Width of } \\
n u k i(\mathrm{~mm})\end{array}$ & $\begin{array}{l}\text { Height of } \\
n u k i(\mathrm{~mm})\end{array}$ & & \\
\hline J1-1 & $\begin{array}{c}\text { Oblique scarf } \\
\text { joint } \alpha n u k i\end{array}$ & 180 & 50 & 120 & Square & $\begin{array}{c}\text { Japanese } \\
\text { cypress }\end{array}$ \\
\hline $\mathrm{J} 1-2$ & $\begin{array}{c}\text { Oblique scarf } \\
\text { joint } \beta \text { nuki }\end{array}$ & 180 & 50 & 120 & Square & $\begin{array}{c}\text { Japanese } \\
\text { cypress }\end{array}$ \\
\hline J6-1 & $\begin{array}{l}\text { Oblique scarf } \\
\text { joint } \alpha \text { nuki }\end{array}$ & 180 & 90 & 120 & Square & $\begin{array}{l}\text { Japanese } \\
\text { cypress }\end{array}$ \\
\hline J6-2 & $\begin{array}{c}\text { Oblique scarf } \\
\text { joint } \beta n u k i\end{array}$ & 180 & 90 & 120 & Square & $\begin{array}{c}\text { Japanese } \\
\text { cypress }\end{array}$ \\
\hline J7-1 & $\begin{array}{l}\text { Oblique scarf } \\
\text { joint } \alpha n u k i\end{array}$ & 240 & 90 & 120 & Square & $\begin{array}{l}\text { Japanese } \\
\text { cypress }\end{array}$ \\
\hline J7-2 & $\begin{array}{c}\text { Oblique scarf } \\
\text { joint } \beta \text { nuki }\end{array}$ & 240 & 90 & 120 & Square & $\begin{array}{l}\text { Japanese } \\
\text { cypress }\end{array}$ \\
\hline s & $\begin{array}{c}\text { Oblique scarf } \\
\text { joint } \alpha \text { nuki }\end{array}$ & 240 & 90 & 180 & Square & $\begin{array}{c}\text { Japanese } \\
\text { cypress }\end{array}$ \\
\hline J8-2 & $\begin{array}{l}\text { Oblique scarf } \\
\text { joint } \beta \text { nuki }\end{array}$ & 240 & 90 & 180 & Square & $\begin{array}{l}\text { Japanese } \\
\text { cypress }\end{array}$ \\
\hline
\end{tabular}
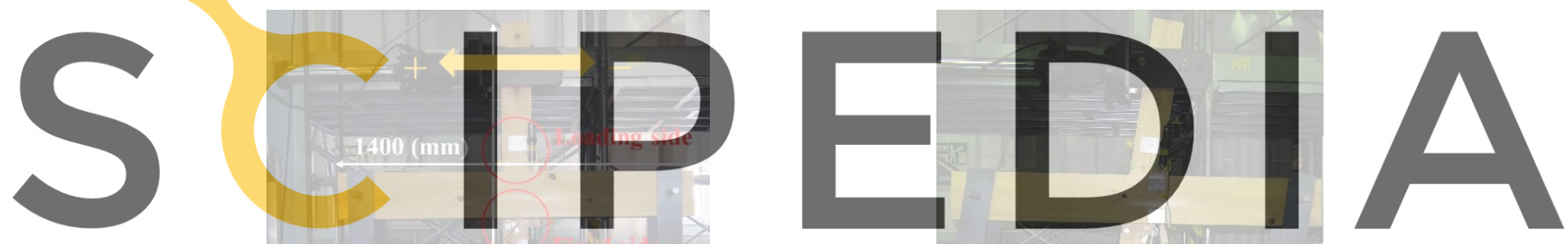

Register for free at https//www.scipedia.com to download the version without the watermark

Figure 2: Loading device apparatus

Figure 3: Loading during full-scale tests

\subsection{Result and discussion of full-scale tests}

Figure 4 illustrates the relationship between the bending moment and deformation angle in the different continuous nuki specimens, as determined via full-scale tests performed in this study. The ultimate bending moment corresponds to a deformation angle of 1/10 rad, including a safety factor of 1.5 , since the collapse limit of traditional wooden buildings is $1 / 15 \mathrm{rad}$.

Images of the failure of continuous nuki are shown in Figure 5. Specimens $\mathrm{C} 1$ to $\mathrm{C} 7$ exhibited cleavage of the wedge. However, the cleavage was not affected by the decrease in bending moment. In $\mathrm{C} 1$ and $\mathrm{C} 2$, the ultimate bending moments demonstrated approximately the same difference for different column shapes. The initial stiffness of $\mathrm{C} 3$ was approximately $70 \%$ less than that of $\mathrm{C} 1$, and the ultimate bending moment of $\mathrm{C} 3$ was approximately $60 \%$ smaller than of $\mathrm{C} 1$, even though the elastic modulus of $\mathrm{C} 3$ was approximately $10 \%$ percent than 
of $\mathrm{C} 1$ in the material test. The ultimate bending moment of $\mathrm{C} 4$ was approximately $10 \%$ smaller than that of $\mathrm{C} 1$, because of the use of the cogged joint. The ultimate bending moment of $\mathrm{C} 1$ was approximately $80 \%$ larger than that of $\mathrm{C} 5$, because of the use of the wedge. Among continuous nuki specimens, the ultimate bending moment of $\mathrm{C} 8$ was the biggest and the ultimate bending moment increased from $\mathrm{C} 1$ to $\mathrm{C} 6$ to $\mathrm{C} 7$ to $\mathrm{C} 8$ because the dimensions of the specimens also increased. It is assumed that the bending moment increased because the dimensions of the specimen increased.

Figure 6 depicts the relationship between the bending moment and deformation angle pertaining to the plus-shaped column-nuki connection with a continuous nuki and the oblique scarf nuki. Results of full-scale tests are depicted in Figures 7. The continuous nuki specimen exhibited embedment failure at first; however, all specimens with the oblique scarf nuki, except for J8-2 first experienced cleavage failure from the kama joint and then bending failure, as shown in Figure 8(a). One kama joint was stuck in the other kama joint at J8-2, as shown in Figures 8(b). Only the specimen with the oblique scarf joint $\beta$ muki exhibited shear failure, as shown in Figure 8(c). The initial stiffness of the continuous and oblique scarf joint nuki specimens with the same dimensions was approximately the same. Both the yield bending moment and ultimate bending moment were approximately 10 to $70 \%$ smaller for the oblique scarf joint $m u k i$ than for the continuous one. In addition, the specimens with oblique scarf joint $\beta$ had both a yield bending moment and ultimate bending moment that was $10 \%$ smaller than that of the specimens with oblique scarf joint abecause oblique scarf joint $\beta$ has steeper angle

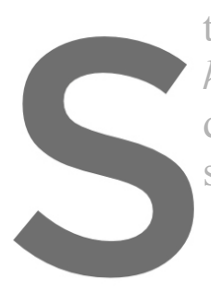
than oblique scarf joint kama joint connection deformation angle was smallen for side until failure.
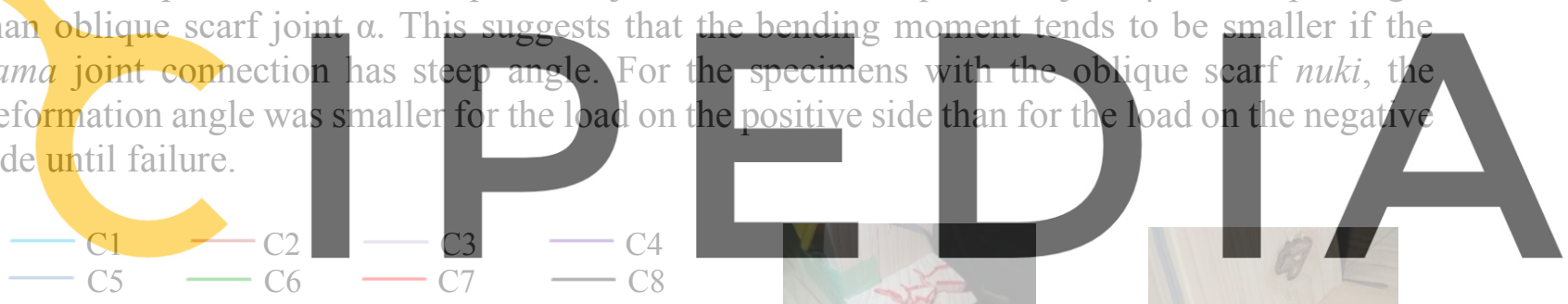

Register for free at https//www.scipedia.com to download the version without the watermark

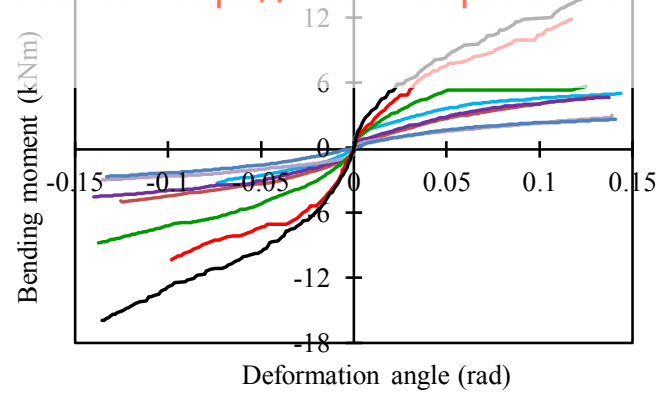

Figure 4: Bending moment vs. deformation angle in full-scale tests (continuous nuki) (a) Cleavage failure of

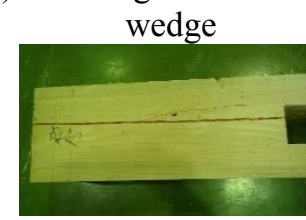

(c) Cleavage failure of column (b) Embedment failure of $n u k i$

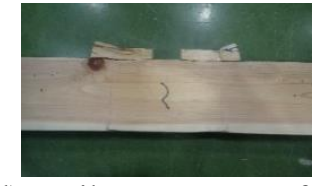

(d) Failure property of nuki

Figure 5: Images of failure (continuous nuki) 


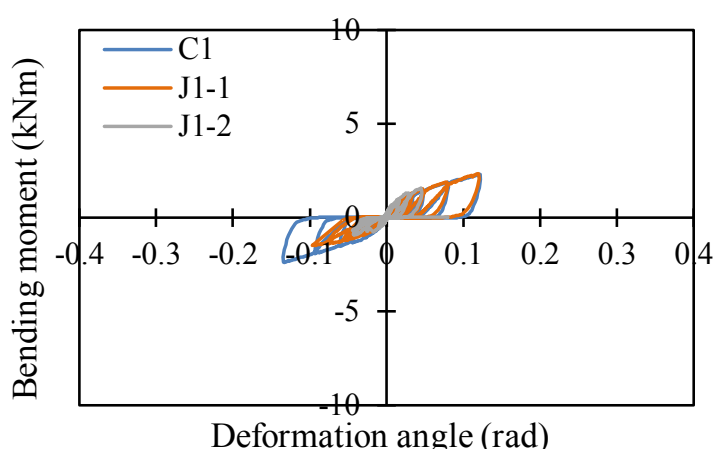

(a) Loading side (C1, J1-1, J1-2)

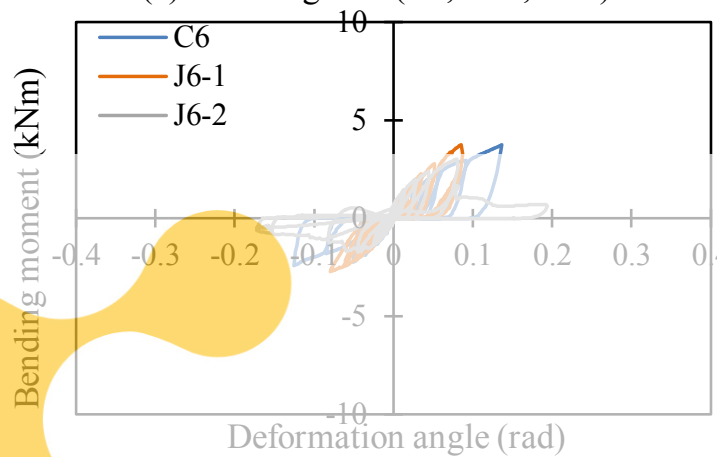

(c) Loading side (C6, J6-1, J6-2)
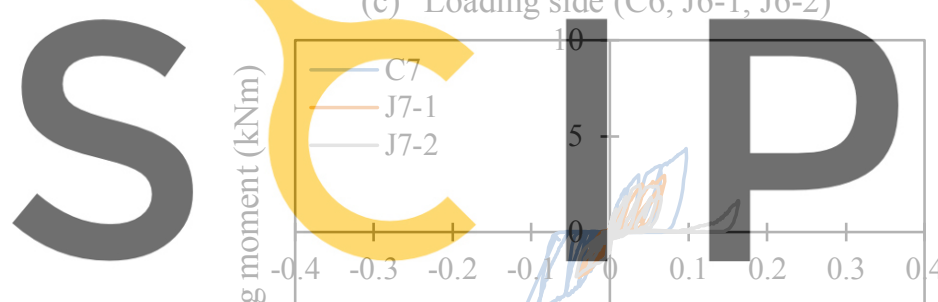

Register for free at https//www.scipedia.com

Deformation angle (rad)

(e) Loading side (C7, J7-1, J7-2)

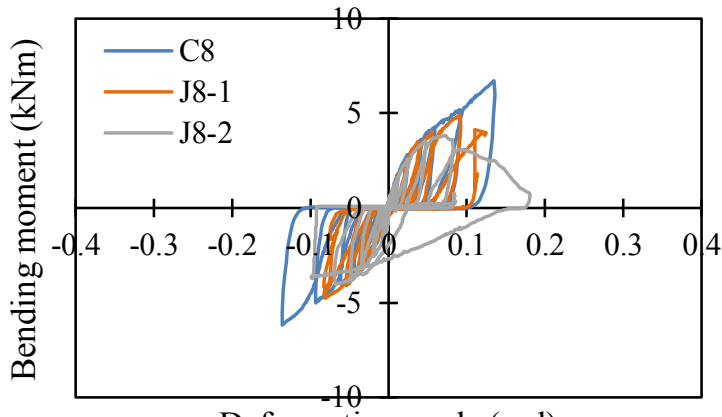

Deformation angle (rad)

(g) Loading side (C8, J8-1, J8-2)

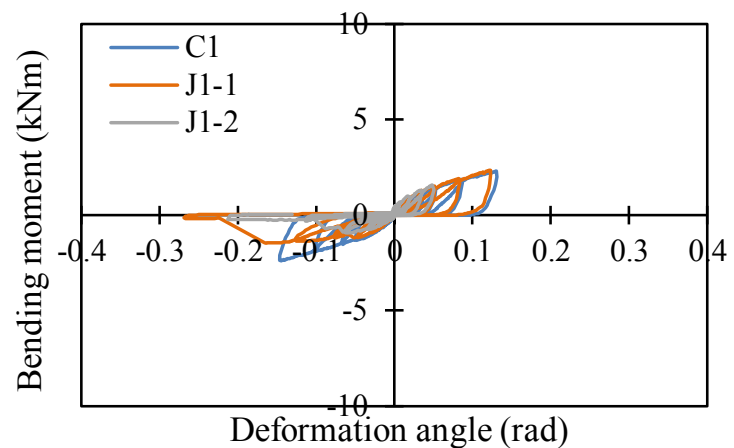

(b) Fixed side (C1, J1-1, J1-2)

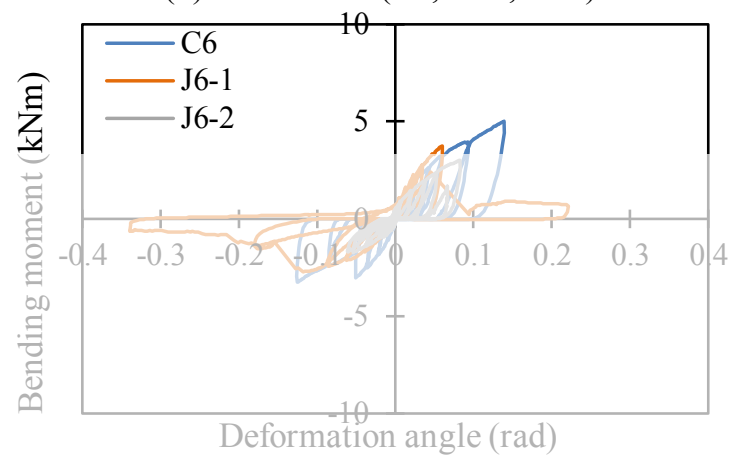

(d) Fixed side (C6, J6-1, J6-2)

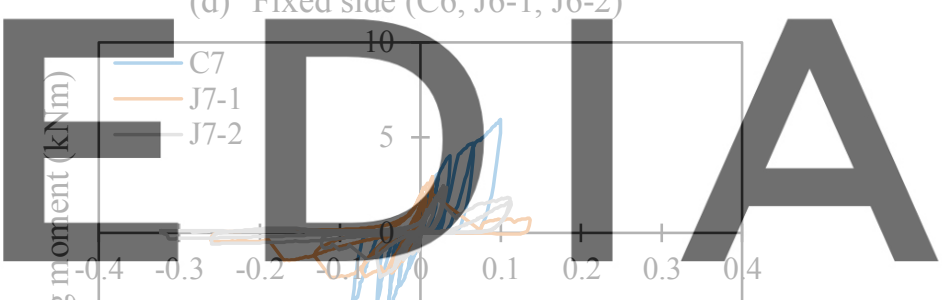

Deformation angle (rad)

(f) Fixed side (C7, J7-1, J7-2)

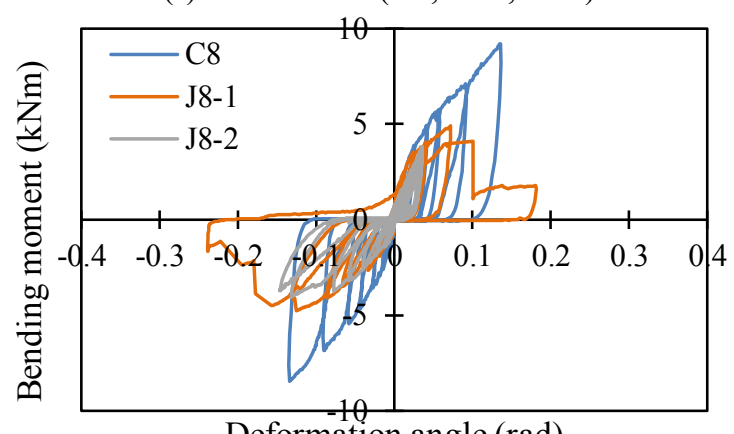

Deformation angle (rad)

(h) Fixed side (C8, J8-1, J8-2)

Figure 6: Relationship between the bending moment and deformation angle 

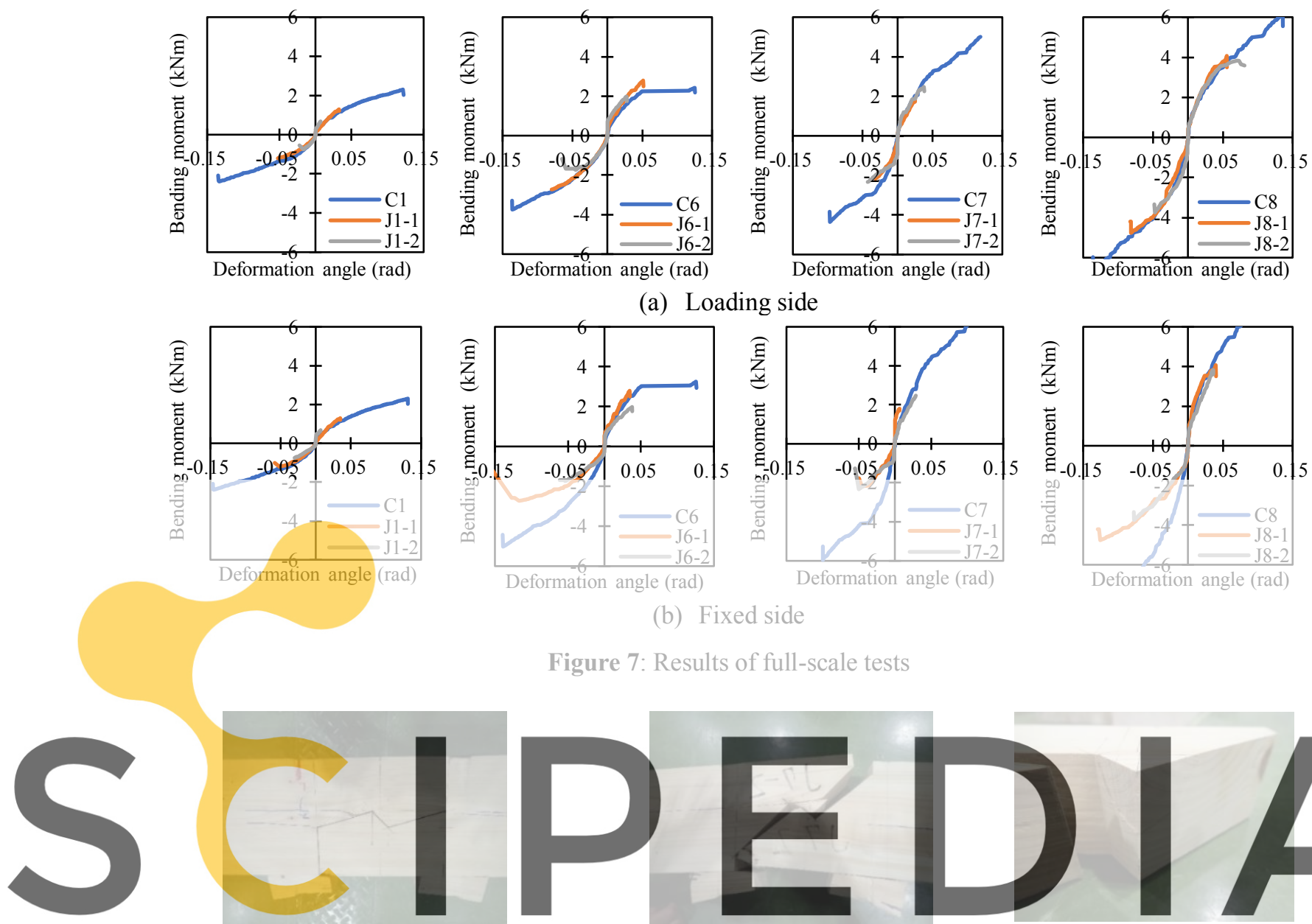

(b) Fixed side

Figure 7: Results of full-scale tests

(a) Cleavage failure from Kama-joint

(b) Kama-joint part of the specimen
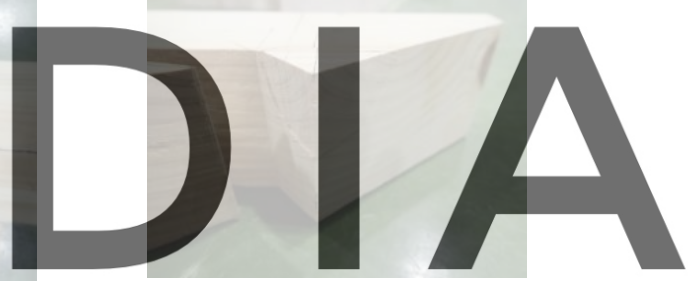

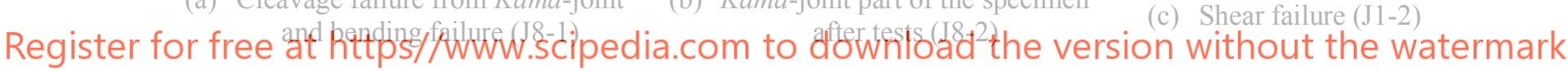
Figure 8: Failure of oblique scarf joint nuki

\section{ESTIMATION EQUATION}

In this study, theoretical results were calculated using the design equation used for continuous nuki in traditional Japanese wooden houses. The rotating stiffness $\left(K_{\theta}\right)$ and yield moment $\left(M_{y}\right)$ were evaluated, and the results were compared with those of the full-scale tests.

\subsection{Outline of estimate equation for continuous $n u k i$}

From the design equation of the continuous nuki [3], $K_{\theta}$ and $M_{y}$ are obtained as follows:

$$
\begin{gathered}
K_{\theta}=x_{p}^{2} y_{p} E_{90}\left\{\frac{x_{p}}{Z_{0}}\left(C_{x m}-\frac{1}{3}\right)+0.5 \mu C_{x m}\right\} \\
M_{y}=\frac{K_{\theta} Z_{0} F_{m}}{x_{p} E_{90} C_{x m} \sqrt{C_{y m}}}
\end{gathered}
$$




$$
\begin{gathered}
F_{m}=\frac{2.4}{3} \times f_{c v} \\
C_{x m}=1+\frac{4 Z_{0}}{3 x_{p}} \\
C_{y m}=1+\frac{4 Z_{0}}{3 n y_{p}} \\
\theta_{y}=\frac{M_{y}}{K_{\theta}}
\end{gathered}
$$

where $x_{p}$ is the diameter of half of the column (mm), $y_{p}$ is the width of the nuki $(\mathrm{mm}), E_{90}$ is the lateral compressive elastic modulus $\left(\mathrm{N} / \mathrm{mm}^{2}\right), Z_{0}$ is the height of the nuki $(\mathrm{mm}), \mu$ is the coefficient of friction ( $\mu=0.4[4]), \theta_{y}$ is the yield deformation angle (rad), $F_{m}$ is the embedment yield unit stress $\left(\mathrm{N} / \mathrm{mm}^{2}\right)$ evaluated from the result of partial compression tests when the edge distance is infinite, $f_{c v}$ is the embedment strength $\left(\mathrm{N} / \mathrm{mm}^{2}\right), C_{x m}$ and $C_{y m}$ are the embedment growth factors in the $x$ and $y$ directions, respectively, when the edge distance is infinite, and $n$ is the displacement factor between the wood fiber direction and the wood fiber

\begin{tabular}{|c|c|c|c|c|c|}
\hline \multirow[t]{3}{*}{ Register } & $\begin{array}{l}\text { Types of } \\
\text { orw6ee a }\end{array}$ & 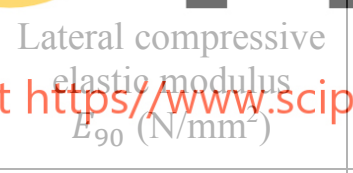 & $\begin{array}{l}\text { Embedment strength } \\
\text { (Partial compressive } \\
\text { edia.comantoh downlc } \\
f_{c v}\left(\mathrm{~N} / \mathrm{mm}^{2}\right)\end{array}$ & $\begin{array}{l}\text { Embedment yield } \\
\text { ad theit stression v } \\
f_{m}\left(\mathrm{~N} / \mathrm{mm}^{2}\right)\end{array}$ & $\begin{array}{l}\text { Second stiffness } \\
\text { withountit stiffness } \\
\text { that }\end{array}$ \\
\hline & $\begin{array}{c}\text { Japanese } \\
\text { cypress }\end{array}$ & 239 & 6.38 & 5.10 & 0.094 \\
\hline & $\begin{array}{c}\begin{array}{c}\text { Japanese } \\
\text { cedar }\end{array} \\
\end{array}$ & 219 & 4.73 & 3.78 & 0.090 \\
\hline
\end{tabular}
radial direction ( $\mathrm{n}$ of Japanese cypress is 6, and $\mathrm{n}$ of Japanese cedar is 5).

Table 3 provides the material constant which is used for calculation and the ratio of the first and second stiffness from the estimate equation

\subsection{Comparison between theoretical and experimental results obtained for continuous nuki specimens}

Figure 9 compares the theoretical and experimental values for each continuous nuki specimen. The theoretical value was calculated using the average lateral elastic modulus from the results of the material tests. In all continuous nuki specimens, the theoretical value of the initial stiffness was greater than the experimental value. This may be caused by the construction tolerances of the specimen and the wood drying shrinkage effect. In addition, the theoretical value, which was calculated using the 50th percentile average of the lateral elastic modulus, was compared with the experimental value to determine the effect of the gap between the column and the nuki. As a result, experimental value was between the theoretical values for all 
specimens except C5. The gap between the column and the nuki in C5 was wider than in the other specimens, because C5 does not have a wedge. Therefore, the experimental results revealed a smaller value than the one that was estimated because the initial stiffness of $\mathrm{C} 5$ became smaller than that of the other specimens.
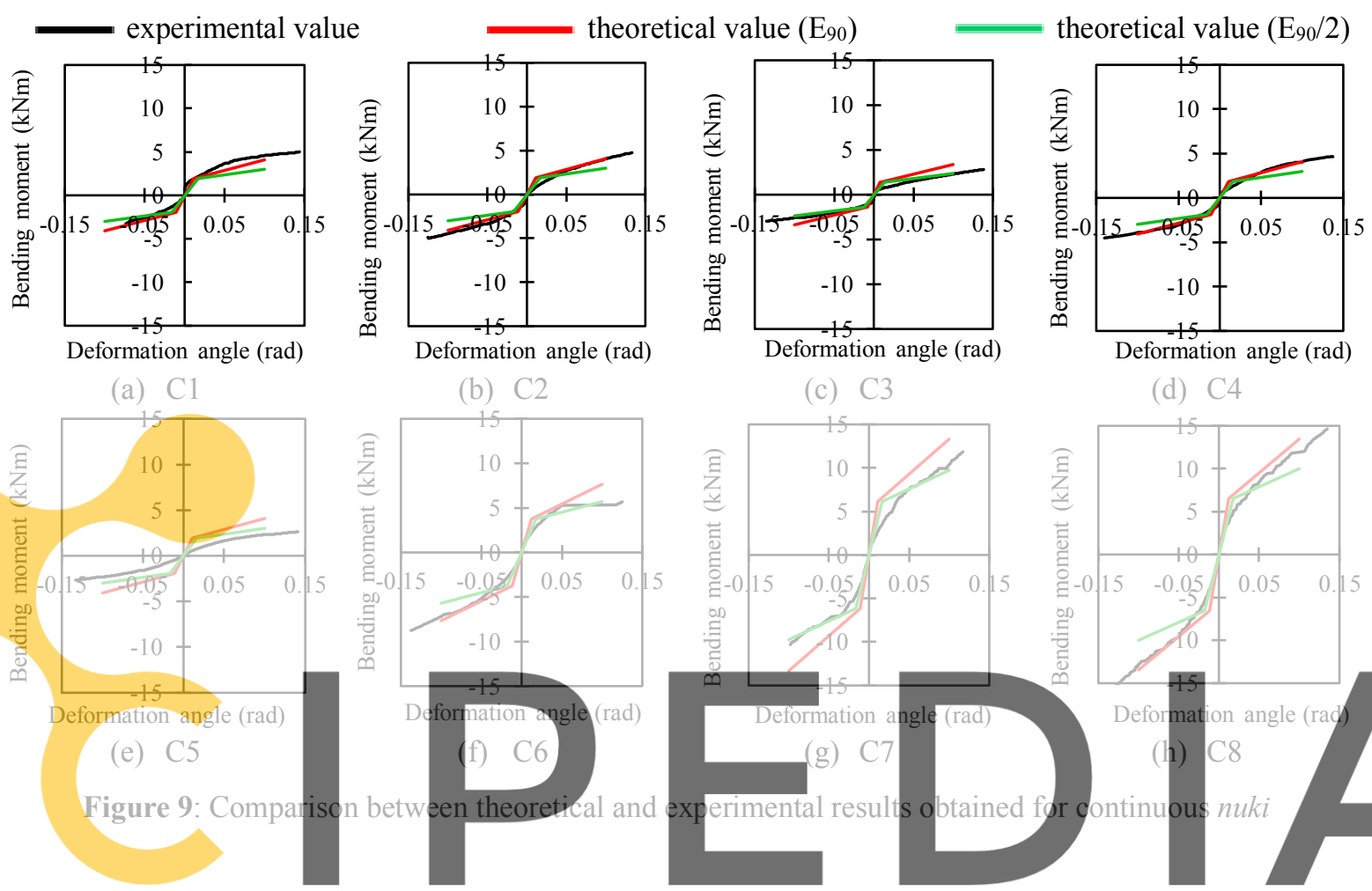

(d) $\mathrm{C} 4$

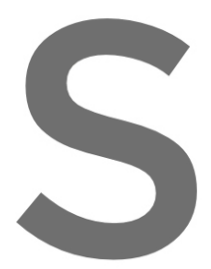

3.3 Estimation equation for oblique scarf joint nuki

Register for free at https//www.scipedia. com to download the version without the watermark

failure, bending failure, shear failure, and cleavage failure. The moment at each failure point

was calculated and compared with the corresponding experimental result. Table 4 shows the material constants used for the calculation of the estimation equation.

To calculate the magnitude of the moment that led to the embedment failure, the rotating stiffness $K_{\theta}$ and yield moment $M_{y}$ were evaluated from the design equation of continuous nuki, which was provided by a previous study [3]. This followed the same procedure that was used for the continuous nuki (equations (1), (2), (3), (4), (5), and (6)). However, the specimens with oblique scarf joint nuki are not symmetrical with respect to the nuki. Therefore, the yield moment $M_{y}$ was divided by two in this case, and the coefficients of friction, $\mu$, were 0.4 and 0.2 on the negative and positive sides, respectively [4].

The moment at the point of bending failure $\left(M_{b}\right)$ was evaluated from the geometrical moment of inertia, $I$, and bending strength, $\sigma_{b}$, as:

$$
M_{b}=\sigma_{b} \times \frac{I}{h_{e} / 2}
$$




$$
I=\frac{y_{p} \times h_{e}{ }^{3}}{12}
$$

where $I$ is the geometrical moment of inertia $\left(\mathrm{mm}^{4}\right), \sigma_{b}$ is the bending strength $\left(\mathrm{N} / \mathrm{mm}^{2}\right)$, and $h_{e}$ is the distance between an edge of the $n u k i$ and the shear plane of the oblique scarf joint $(\mathrm{mm})$, as shown in Figure 10.

The moment at the point of shear failure $\left(M_{s}\right)$ was evaluated from the shear strength, $\tau$, as:

$$
M_{s}=\alpha y_{p} \tau h_{e}
$$

where $\tau$ is the shear strength $\left(\mathrm{N} / \mathrm{mm}^{2}\right)$ and $\alpha$ is the shear distance $(\mathrm{mm})$.

The moment at the point of cleavage failure $\left(M_{u w}\right)$ was evaluated using a design equation [5] for cleavage failure if a nuki is stressed from the wood fiber and radial direction by equations (10) and (11).

$$
\begin{gathered}
M_{s}=P_{u w} h_{e} \\
P_{u w}=\frac{2}{1} C_{r} y_{p} \sqrt{\frac{h_{e}}{1-\frac{h_{e}}{Z_{0}}}}
\end{gathered}
$$

where $P_{u w}$ is the ultimate strength caused by the cleavage failure and $C_{r}$ is a cleavage failure constant $\left(\mathrm{N} / \mathrm{mm}^{1.5}\right)\left(\right.$ Japanese cypress $\left.C_{r}=10.0\left(\mathrm{~N} / \mathrm{mm}^{1.5}\right)\right)$.
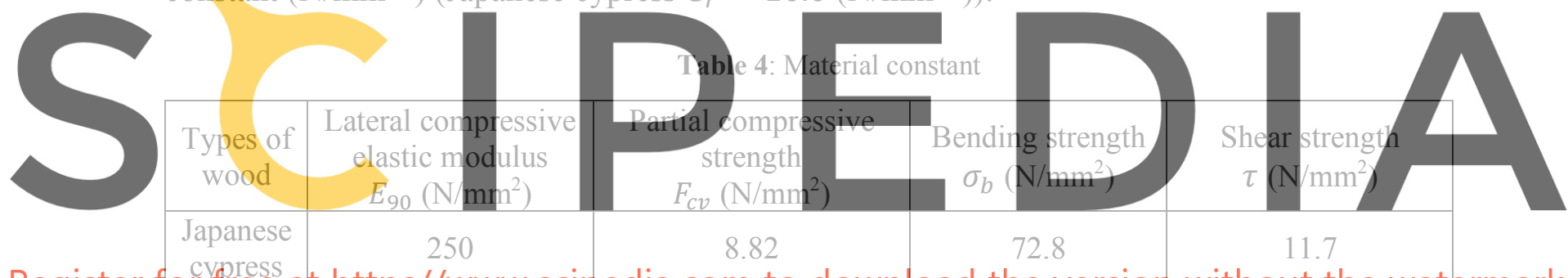

Register forfyree at https//www.scipedia.com to download the version without the watermark

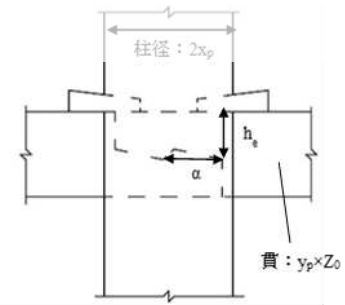

Figure 10: the detail of joint

\subsection{Comparison between theoretical and experimental results obtained for oblique scarf joint nuki specimens}

Figure 11 compares the moments at bending failure, embedment failure, shear failure, and cleavage failure with their associated experimental values for the oblique scarf joint nuki specimens. In Figures $11(\mathrm{~g})$ and $(\mathrm{h})$, the moments at the points of bending and shear failure exceeded $10 \mathrm{kNm}$, and hence these are not shown in the graph. 
All specimens with an oblique scarf joint nuki first exhibited cleavage failure in the nuki, followed by multiple failures. The moment at cleavage failure was the smallest and corresponded to the experimental value. The specimens with an oblique scarf joint nuki were already subjected to cleavage failure before the failure was confirmed visually around the $n u k i$ in the full-scale tests. This was because the cleavage failure occurred in the part of the columnnuki joint that is visually inaccessible from the outside. Furthermore, J1-2, J6-2, and J8-2, specimens that exhibited shear failure within the joint after failure, experienced the moment of shear failure.

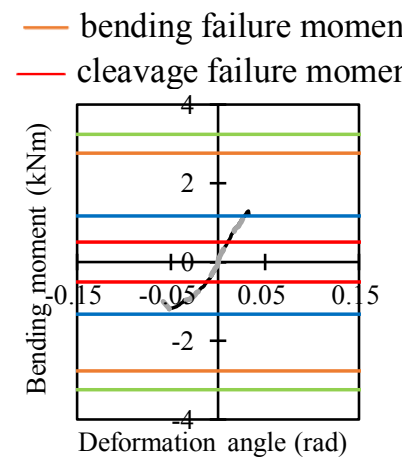

(a) $\mathrm{J} 1-1$

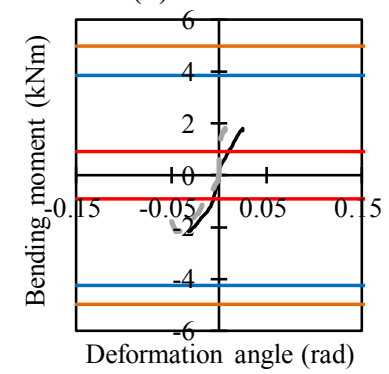

(a) $\mathrm{J} 7-1$

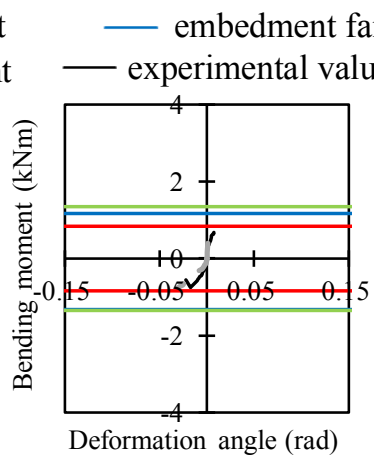

(b) $\mathrm{J} 1-2$

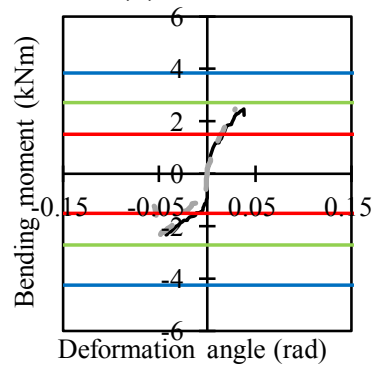

(b) J7-2

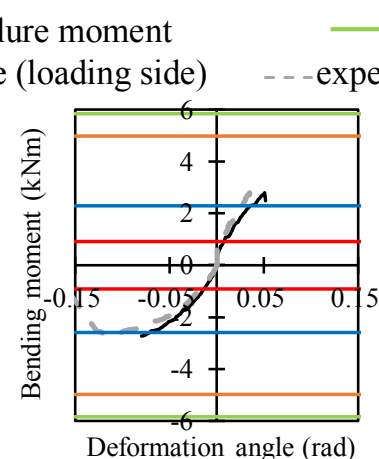

(c) J6-1

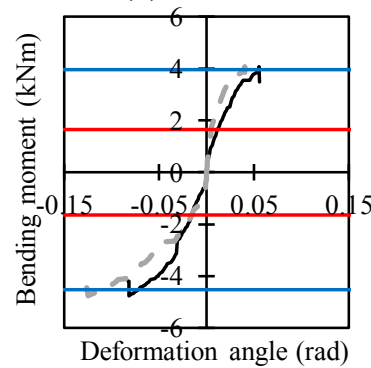

(c) J8-1
— shear failure moment -experimental value (fixed side) (d) J6-2

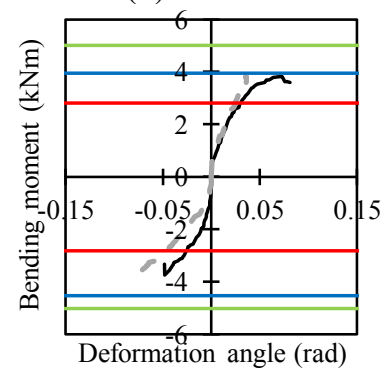

(d) J8-2

Figure 11: Comparison between theoretical and experimental results obtained for oblique scarf joint nuki

\section{CONCLUSIONS}

We performed full-scale tests to obtain the relationship between the bending moment and deformation angle and failure property of plus-shaped column-nuki connections, which of either the continuous or oblique scarf joint nuki type. Furthermore, the theoretical values were calculated using the design equation, and the experimental and theoretical values were compared. The main findings of this study are as follows:

Continuous nuki specimens showed cleavage failure at the wedge or column in the fullscale tests; however, this was not affected by the decrease in the bending moment. All oblique scarf joint nuki specimens showed cleavage failure first in the nuki, followed by multiple failures. The full-scale test results showed that the yield and ultimate bending moment of oblique scarf joint nuki specimens were approximately 10 to $70 \%$ smaller than those of the corresponding continuous nuki specimens.

- In continuous nuki specimens, the initial stiffness of the theoretical value was higher 
than the experimental one. In addition, the experimental value expected for the C5 specimen without the wedge was within the range of the theoretical values that were calculated using the average lateral elastic modulus and the theoretical values that were calculated using half of the average lateral elastic modulus. The gap between the column and the nuki in the specimen without a wedge was bigger than the gap in the other specimens. Therefore, the experimental value of the specimen without the wedge was less than the theoretical one due to the small initial stiffness.

- $\quad$ In the oblique scarf joint nuki specimens, the theoretical value of cleavage failure was the smallest, and it coincided with the experimental value. Regarding bending failure and shear failure, the experimental bending moment was smaller than the theoretical value.

The results demonstrated that failure can be partially estimated using the previous design equation by comparing theoretical to experimental values; however, the experimental data on plus-shaped column-nuki connections which have oblique scarf joint nuki is still insufficient. In the future, more full-scale tests of plus-shaped column-nuki connections can be performed, and finite element analysis can be used to create a model which corresponds to various failure properties.

Acknowledgements. This research was supported by the Matsui Kakuhei Memorial Foundation. We gratefully acknowledge this support.

\section{REFERENCES}

[1] Kaori Fujita, Isao Sakamoto, Yoshimitsu Ohashi: A Study on lateral loading test of column and batten (nuki) joint used in traditional wooden architecture (Part 1), Summaries of Technical Papers of Annual Meeting, Architectural Institute of Japan, Structures-III, pp. 103-104, 1996.09 (in Japanese)

[2] Editorial Committee for Manual of Seismic Design for Wooden Frame Structures: Manual of Seismic Design for Wooden Structures Taking Advantage of Traditional Structural Techniques - Methods for Seismic Design and Seismic Reinforcement Design Based on Response-Limit Capacity Analysis -, Gakugei Shuppan Sha Co. Ltd., Japan, March 2004, pp.79

[3] Architectural Institute of Japan (edited): Design Manual for Engineered Timber Joints, Maruzen, Japan, September 2010, pp. 254-257.

[4] Japan Housing and Wood Technology Center: Project Report about points to consider for design of timber structures (in Japanese), March 2018, pp. 216-226.

[5] Architectural Institute of Japan (edited): Standard for Structural Design of Timber Structures, Maruzen, Japan, March 2009, pp. 36-37. 